\title{
Homage To Prof. Abu Zafar
}

\section{Abdullah Al Shafi Majumder}

(Cardiovasc. j. 2020; 13(1): 1-2)

A teacher of finest quality, Prof Abu Zafar was the pioneer in echocardiography in Bangladesh. He was one of the legendary figures in cardiovascular science who shaped the foundation of the apex centre of the country, Institute of Cardiovascular Diseases (ICVD, later NICVD).

As a teacher he emphasized on the clinical and practical aspects of the learning rather than being theoretically conversant. He taught us that wards are more a learning place than the library. While he gave lessons in the wards, he asked the students to find out clinical signs before the investigations. Pulse, jugular veins, apex beat, heave, thrill were his favorite topics of discussion in the classes. All the students who were fortunate to attend his classes will agree to this point and his words so much imprinted in our brain that we still remember the way he taught us.

Another subject he chose to make us interested was electrocardiogram. He used to read it very minutely and inspired us to do so. Whenever he had any interesting (sometimes tricky) ECG, he showed it not only to the students he showed to the fellow junior teachers and asked their opinion. By this way, there was an academic ambience in the institute. He used to throw many questions which seemed simple but answers were difficult to find out. We remained busy searching for the answers and came through many new information during that search.

He loved to do echocardiography systematically. In those days echo was not so widespread and

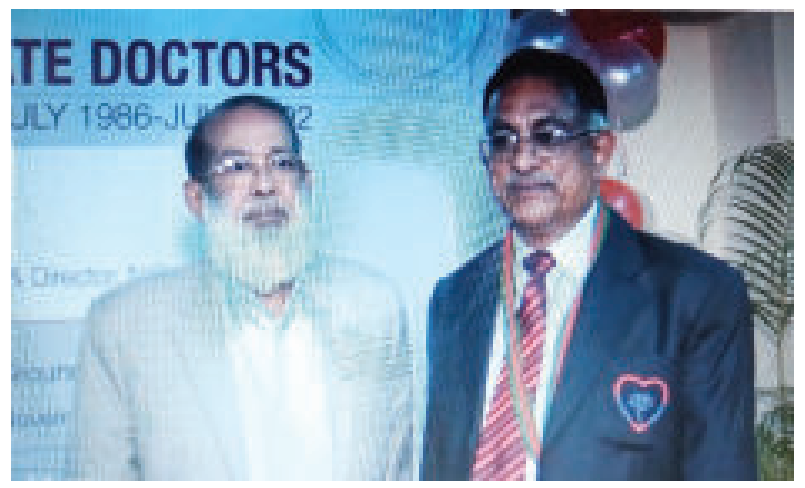

At NICVD : 27.11.2014 knowledge was very limited. He was the person who imparted to his juniors the knowledge of basic echocardiography. He taught us echo literally by hands. It is not exaggeration if I say that the seniors who earned reputation in doing echo in these days are the products of his hands-on training. It was he who started saline contrast echo to diagnose atrial septal defect.

In those early days of the institute there was a Cath lab in the hospital (provided by JICA). Besides cardiac catheterization there were few cases of coronary angiogram and interventional cardiology was yet to develop. One important use of Cath lab was pacemaker implantation and Prof Zafor was considered the most judicious in the procedure. We witnessed him to implant a pacemaker of Prof Mohammed Ibrahim. He used to teach us the basics of pacemaker.

As an examiner, he was simple asking very basic aspects. It was said that if one failed in the examination facing Prof. Zafar, he understood the rationality of his failure. He never made tricks on the examinee. He was tough on ignorance but generous on knowledge of his students.

Prof Abu Zafar took charge of the Director of the NICVD in 1989 after the retirement of Prof (Brig) Abdul Malik, the Founder-Director. He never compromised with any ethical issues as an administrator. He always kept his head high though there were conspiracy against him organized by some quarters including his colleagues. He had to leave the post in 1994 to join the IPGM\&R as

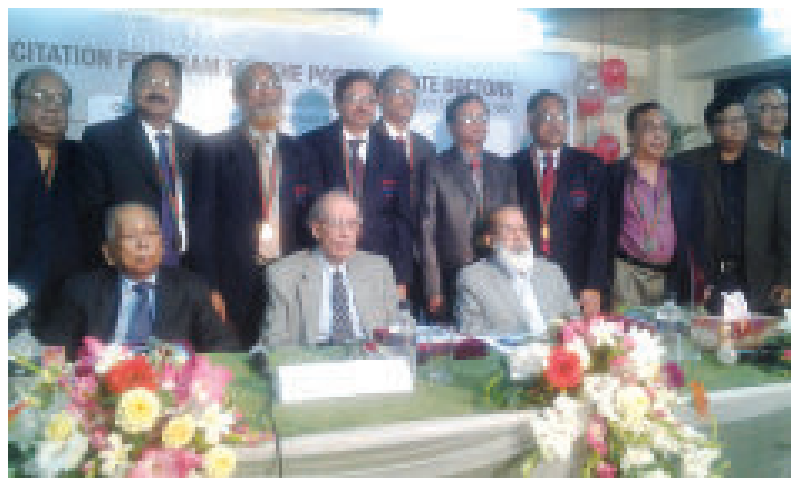

Felicitation program for Post-graduate doctors, NICVD, 27.11,2014 
the Professor of Cardiology till 1996 at his retirement time.

After retirement he withdrew from all public activities. He refused to become even examiner of the Dhaka University or BCPS examination. He declined any invitation to attend the scientific meetings. Though I could bring him in a meeting at the Institute with the students in the early period of the institute where the teachers of that period were invited. After a few years of his retirement he abandoned private practice thus making himself an isolated person.
In most time he was a reserved person but he was witty using satirical words to express his inner feeling. A man of good taste he maintained sophistication in his behavior. Sometimes we could not understand fully his mood and attitude.

By any measure he was the most charismatic figure in the Institute. His pursuit for knowledge amazed us; his love for perfection was the inspiration for his students; his way of dealing with other people was a learning for us; his attachment to ethical and moral values was the example for us who like to pursue those and indeed he was role-model for his next generation doctors. 